\title{
Theoretical Study for Chemical Reactivity Descriptors of Tetrathiafulvalene in gas phase and solvent phases based on Density Functional Theory
}

\author{
Yousif H. Azeez ${ }^{1}$, Hanaa SH. Ahmed ${ }^{2 *}$ \\ ${ }^{1}$ Department of Physics, College of Science, University of Halabja, Halabja, Kurdistan Region, Iraq \\ ${ }^{2}$ Department of Physics, College of Education, University of Garmian, Kalar, Kurdistan Region, Iraq
}

Received 18 April 2021; revised 01 June 2021;

accepted 05 June 2021; available online 30 June 2021

doi: $10.24271 /$ psr. 28

\begin{abstract}
The aim of the study is to investigate the effects of solvent polarity on the frontier molecular orbitals energy gap and global chemical reactivity of Tetrathiafulvalene in order to understand the stability and reactivity of Tetrathiafulvalene in a different solvent medium. Density functional theory with (B3LYP/6-311++G) basis set was used to perform a variety of calculations in both the gas and solvent phases. Besides dipole moment, Mulliken charge distribution, and thermodynamic properties were calculated in five solvent phases namely (water, acetone, Tetrahydrofuran (THF), Carbon tetrachloride $\left(\mathrm{CCl}_{4}\right)$, and benzene). The calculations were carried out using the Gaussian 09 software, and the results showed that the solvents have an effect on the optimized parameters. Moreover, Mulliken population analysis, and local reactivity as Fukui Functions (FFs) from the natural bond orbitals (NBO) charges are computed to understand the electrophile, nucleophile region, and chemical activity of the title molecule. The dipole moment in gas phase and solvent medium is 0.00 Debye. Also, it was observed that the global chemical reactivity parameters change depending on the molecular structure and polarity of the solvents. Tetrathiafulvalene molecule was observed to have greater stability (low reactivity) in the water solvent with an $\mathrm{E}_{\text {Hомо- }} \mathrm{E}_{\mathrm{LUmO}}$ energy gap of $3.946 \mathrm{eV}$ while it has higher reactivity (low stability) in the gas phase with $\mathrm{E}_{\mathrm{HO} о}-\mathrm{E}_{\mathrm{LUmO}}$ energy gap of $3.872 \mathrm{eV}$. finally, this result indicates that Tetrathiafulvalene is an excellent candidate for future studies of semiconductor and optoelectronic materials.
\end{abstract}

(C) 2021 Production by the University of Garmian. This is an open access article under the LICENSE

https://creativecommons.org/licenses/by-nc/4.0/

Keywords: Density functional theory; Fukui functions (FFs); global and local chemical reactivity descriptors, Dipole Moment, Mulliken population analysis, Fukui Functions (FFs)

\section{Introduction}

Tetrathiafulvalene (TTF) is a type of organic semiconductor that has attracted a lot of attention in recent years as potential charge transfer material in organic electronic systems. It contains 14 atoms and 104 electrons; however, it has a higher capacity for donating electrons. TTFs were produced and widely used as electron donors to generate charge transfer complexes in the creation of organic conductors and supramolecular chemistry ${ }^{[1-}$ 3].

Many experts from biology, pharmacology, and chemistry have worked on the TTF in recent years, revealing information about this chemical and its derivatives. Tahar Abbaz et.al. studied the reactivity of tetrathiafulvalene with derivatives and focused on

* Corresponding author

E-mail address: hanaa.shahab@garmian.edu.krd (Instructor).

Peer-reviewed under the responsibility of the University of Garmian. molecular structure and chemical reactivity of some pnitrophenyl Tetrathiafulvalene ${ }^{[4]}$. D. Jeroundi, et.al calculated the quantum chemistry calculation parameters of TTF and derivatives ${ }^{[5]}$.Hendrik, et.al. investigated how to control motion in mechanically interlocked molecules ${ }^{[6]}$. Huixin, et.al. explored the interactions between tetrathiafulvalene units in dimeric structures ${ }^{[7]}$. P. Gnanamozhi, at.al. dealt with the structure and FMOs gap of Tetrathiafulvalene (TTF) as organic superconductors ${ }^{[8]}$.

In the recent years, the Density Functional Theory (DFT), has been the most common quantum chemical method used for calculating different molecular properties such as physical, chemical and biological systems ${ }^{[9,10]}$. Chemical descriptors were described by DFT for studying and forecasting reactivity indices and selectivity ${ }^{[11-18]}$.

The objective of this study is to analyze Frontier Molecular Orbitals (FMOs) energies and obtain global reactivity descriptors. Moreover, Mulliken population analysis and Fukui Functions (FFs) were calculated to determine the atomic charge 
distribution for selecting electrophile and nucleophile areas of the TTF compound using DFT with a basis set (B3LYP/6-311++G).

\section{Materials and Methods}

The optimized structure of TTF was performed on personal computer using the Gaussian 09W software packages developed by Frisch and coworkers. Gaussian output files were visualized by means of Gaussian View 06programme. The theoretical calculations were performed to investigate the geometric parameters and electronic properties of this compound such as ionization potential (I), electron affinity (A), lowest unoccupied molecular orbital (ELUMO), highest occupied molecular orbital ( $\mathrm{E}_{\text {НОмО }}$ ), and energy gap $\left(\mathrm{E}_{g}\right)$. Koopman's theorem for closedshell molecules can be used to compute the various global chemical reactivity descriptors in different types of solvents. Mulliken population analysis, Fukui functions, and thermodynamic parameters can be computed and discussed ${ }^{[19-26]}$.

\section{Results and Discussion}

\section{1. Global Reactivity Descriptors and Dipole Moment}

The molecular structures of TTF compound were optimized using the quantum mechanical method at the B3LYP/6-311++G basis set in gas phase and in solvents. The global chemical reactivity descriptors in (Table 1and Table 2) such as ionization potential (I), electron affinity (A), lowest unoccupied molecular orbital ( $\left.\mathrm{E}_{\mathrm{LUMO}}\right)$, highest occupied molecular orbital ( $\left.\mathrm{E}_{\mathrm{HOMO}}\right)$, and energy gap $\left(\mathrm{E}_{g}\right)$. electronegativity $(\chi)$, chemical potential $(\mu)$, molecular hardness $(\eta)$, molecular softness $(\mathrm{s})$, electrophilicity index $(\omega)$, Nucleofugality $\left(\Delta \mathrm{E}_{n}\right)$, and Electroofugality $\left(\Delta \mathrm{E}_{n}\right)$ in different types of solvents using equations (1-8) as shown below ${ }^{\text {[27-30]. }}$

$E_{g}=\mathrm{I}-\mathrm{A}$

$\chi=\frac{\mathrm{I}+\mathrm{A}}{2}$

$\mu=\frac{-(\mathrm{I}+\mathrm{A})}{2}$

$\eta=\frac{\mathrm{I}-\mathrm{A}}{2}$

$S=\frac{1}{2 \eta}$

$\omega=\frac{\chi^{2}}{2 \eta}$

$\Delta \mathrm{E}_{n}=\frac{(\eta-\chi)^{2}}{2 \eta}$

$\Delta \mathrm{E}_{e}=\frac{(-\chi-\eta)^{2}}{2 \eta}$

Where, $\mathrm{I}$ is ionization potential $\left(\mathrm{I}=-\mathrm{E}_{\mathrm{HOMO}}\right)$ and $\mathrm{A}$ is electron affinity $\left(\mathrm{A}=-\mathrm{E}_{\mathrm{LUMO}}\right)$.

Molecules with large HOMO-LUMO gaps are named hard molecule, meanwhile molecules with a small gap of HOMOLUMO are referred to as soft molecules. The stability and reactivity of the molecule to softness and hardness can be linked. A molecule with a small HOMO-LUMO gap is more reactive (soft) and big HOMO-LUMO gap is more stable (hard).
The global chemical reactivity descriptors such as hardness $(\eta)$, softness (S), electronegativity $(\chi)$, chemical potential $(\mu)$, electrophilicity index $(\omega), \quad$ nucleofugality $\left(\Delta \mathrm{E}_{n}\right)$, electrofugality $\left(\Delta \mathrm{E}_{n}\right)$ could be calculated from HOMO and LUMO energy orbitals achieved in the gas phase and solvents phase by using density functional theory with B3LYP/6-311++G basis set of TTF molecular structure as shown in Figure1.

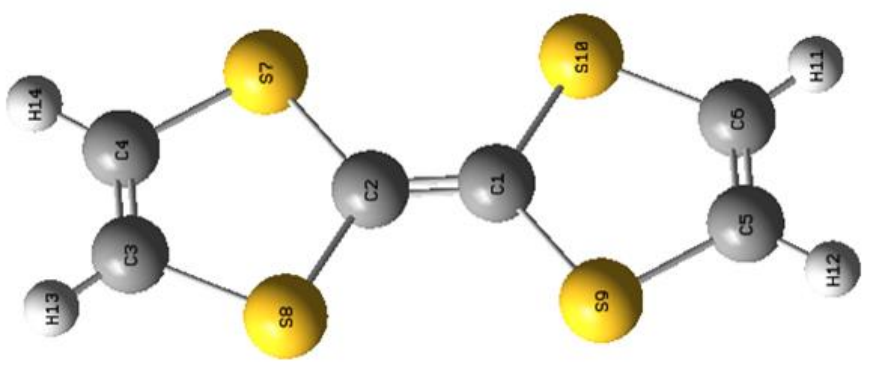

Figure 1: Optimized structure of TTF compound

One of the main components in this study is the effect of solvents, which determines the rate of chemical reaction dependent on polarity. The chemical structure of this substance is related to changes in the values of global chemical reactivity characteristics in the solvent phases. The electronic affinity (A) is a measure of the capacity of the compound to gain valence electrons, while ionization potential (I) is a measure of the ability of the compound to lose electrons. The higher value of ionization potential energy(I) parameter indicates that it is difficult to eliminate electron to form an ion, whereas a molecule with a high value of electron affinity (A) signifies that it is difficult to add electron. As can be seen in Table 1, it is difficult to remove an electron from the gas phase to the solvent phase to form an ion as a result of the higher value of ionization potential. On the other hand, the smaller the electron affinity, the simpler it is to add an electron to create an ion.

Water and several polar solvents are incapable to create significant attractive interactions with non-polar molecules because the hydrogen and carbon atoms are well bonded together through non-polar vander waals interactions.

The frontier energy gap, $\mathrm{E}_{\text {HOMO, }}$ and $\mathrm{E}_{\mathrm{LUMO}}$ energy of TTF in the gas phase and solvents phase are determined by density functional theory with the basis set (B3LYP/6-31++G). The HOMO-LUMO gap is strongly related to the optical and electronic properties of TTF. The HOMO energy denotes the ability to give electrons, whereas the LUMO energy denotes the ability to receive electrons. The energy gap between HOMOLUMO orbitals characterizes molecular chemical stability, optical polarizability, and chemical reactivity. The smaller the energy gap (soft) between LUMO and HOMO energy orbitals, the easier it is for the HOMO electron to be transferred to an excited state (LUMO). The wider the energy gap, the more difficult it is for the (HOMO) to donate an electron to the excited state (LUMO). TTF has a lower energy gap in $\mathrm{CCl}_{4}(3.899 \mathrm{eV})$ than gas phase and other solvents.

Consequently, the electron transfer from HOMO to LUMO of the molecule in $\mathrm{CCl}_{4}$ is comparatively easier than that in the gas phase and other solvent phases. TTF has a greater bandgap energy in water $(3.984 \mathrm{eV})$ than in the gas phase and the rest of the solvent phases, as indicated in Table 2. Therefore, the electron transfer from HOMO to LUMO of the molecule in water is 
relatively harder than that in the gas phase. The bandgap energy of this compound in the gas phase is $3.872 \mathrm{eV}$, and this result is an agreement with the calculated values in ${ }^{[31,32]}$. As seen in Table
1 , the electron jumps from the HOMO to the LUMO energy orbital more easily (softer) in the gas phase than in the other solvent phases combined.

Table 1: Ionization energy, potential energy, HOMO, LUMO, and energy gap of TTF in the gas phase and diverse solvents

\begin{tabular}{|l|c|c|c|c|c|c|}
\hline \multirow{2}{*}{$\begin{array}{l}\text { Tetrathiafulvalene } \\
\left(\mathbf{C}_{\mathbf{6}} \mathbf{H}_{\mathbf{4}} \mathbf{S}_{\mathbf{4}}\right)\end{array}$} & \multicolumn{7}{|c|}{ Calculations } \\
\cline { 2 - 7 } $\mathbf{I P}(\mathbf{e V})$ & Gas phase & Water & Acetone & THF & CCL4 & Benzene \\
\hline EA $(\mathbf{e V})$ & 5.109 & 5.263 & 5.250 & 5.222 & 5.159 & 5.155 \\
\hline $\mathbf{E}_{\text {HOMо }}(\mathbf{e} \mathbf{V})$ & 1.237 & 1.317 & 1.308 & 1.291 & 1.260 & 1.255 \\
\hline $\mathbf{E}_{\mathbf{L U M O}}$ & -5.109 & -5.263 & -5.250 & -5.222 & -5.159 & -5.155 \\
\hline $\mathbf{E}_{\mathbf{g}}(\mathbf{e V})$ & -1.237 & -1.317 & -1.308 & -1.291 & -1.260 & -1.255 \\
\hline
\end{tabular}

Electronegativity and the electronic chemical potential are important parameters in the quantum chemical reaction. The more the value of electronegativity, the greater the capability of atoms or molecules to attract electrons, whereas the greater the value of chemical potential value, the more the reactivity and less stability. This molecule in water has a higher electronegativity than other solvents as shown in Table 2. TTF has the maximum chemical potential in the gas phase and benzene solvent. As a result, this molecule is more reactive and less stable in both gas phase and benzene solvent, as seen in Table 2. The electrophilicity index magnitude is used as a chemical structural descriptor for the examination of the chemical reactivity of molecules. More reactive nucleophile is considered to have a lower value of $(\omega)$ than a strong electrophile with a high value of $(\omega)$. As shown in Table 2, TTF in benzene solvent is a more reactive nucleophile, indicating that this molecule is a good electrophile when compared to water solvent. Electrofugality and nucleofugality are important concepts to describe the chemical reaction. Due to the greater polarity of water compared to the gas phase and the other solvents, TTF in water has the highest electrofugality and nucleofugality.

Table 2: Global chemical reactivity descriptors of TTF in the gas phase and different types of solvent

\begin{tabular}{|l|c|c|c|c|c|c|}
\hline \multirow{2}{*}{$\begin{array}{l}\text { Tetrathiafulvalene } \\
\left(\mathbf{C}_{\mathbf{6}} \mathbf{H}_{4} \mathbf{S}_{\mathbf{4}}\right)\end{array}$} & \multicolumn{7}{|c|}{ Calculations } \\
\cline { 2 - 7 } $\boldsymbol{\eta}(\mathbf{e V})$ & Gas phase & Water & Acetone & THF & CCL $_{4}$ & Benzene \\
\hline $\boldsymbol{S}(\mathbf{e V})^{-\mathbf{1}}$ & 1.936 & 1.973 & 1.971 & 1.966 & 1.949 & 1.950 \\
\hline $\boldsymbol{\chi}(\mathbf{e V})$ & 0.258 & 0.253 & 0.254 & 0.254 & 0.257 & 0.256 \\
\hline $\boldsymbol{\mu}(\mathbf{e V})$ & 3.173 & 3.290 & 3.279 & 3.255 & 3.210 & 3.205 \\
\hline $\boldsymbol{\omega}(\mathbf{e V})$ & -3.173 & -3.290 & -3.279 & -3.255 & -3.210 & -3.205 \\
\hline $\boldsymbol{\Delta E}_{\boldsymbol{n}}(\mathbf{e V})$ & 2.600 & 2.743 & 2.725 & 2.742 & 2.710 & 2.703 \\
\hline $\mathbf{\Delta E}_{\boldsymbol{e}}(\mathbf{e V})$ & 0.395 & 0.440 & 0.434 & 0.423 & 0.409 & 0.404 \\
\hline
\end{tabular}

The dipole moment parameter is expressed in Debye (D) unit. The stronger the intermolecular interactions, the bigger the magnitude of the dipole moment. Similarly, the larger the magnitude of the dipole moment, the more polar the molecule ${ }^{[31}$ 34]. The zero value of the dipole moment specified that TTF is a nonpolar molecule as presented in Table 3 .

Table 3: Effects of solvent polarity on the value of dipole moment of TTF

\begin{tabular}{|l|c|c|c|c|c|c|}
\hline $\begin{array}{l}\text { Dipole moment } \\
\text { (Debye) }\end{array}$ & Gas phase & Water & Acetone & THF & Benzene & CCL4 \\
\hline X & 0.000 & 0.000 & 0.000 & 0.000 & 0.000 & 0.000 \\
\hline Y & 0.000 & 0.000 & 0.000 & 0.000 & 0.000 & 0.000 \\
\hline Z & 0.000 & 0.000 & 0.000 & 0.000 & 0.000 & 0.000 \\
\hline Total & 0.000 & 0.000 & 0.000 & 0.000 & 0.000 & 0.000 \\
\hline
\end{tabular}

\section{2. Mulliken Population Analysis and Fukui Functions}

The calculation of the Mulliken atomic charge is essential in the application of the molecular system for quantum chemical computation. The Mulliken population analysis influences several molecule attributes, such as dipole moment, electronic structure, and other chemical system properties. The distribution of positive and negative charges has a significant impact on the length of the connection between the atoms ${ }^{[35,36]}$. The atomic charge on the $\mathrm{C}_{6} \mathrm{H}_{4} \mathrm{~S}_{4}$ compound is negative (1C, $2 \mathrm{C}, 3 \mathrm{C}, 4 \mathrm{C}, 5 \mathrm{C}$, $6 \mathrm{C}$ ) and positive (7S, 8S, 9S, 10S), with the full atomic charge on hydrogen atoms being positive. As shown in Table 4, the existence of substantial negative atomic charges on (1C and 2C) in the gas phase and solvent mediums such as benzene and $\mathrm{CCl}_{4}$ indicates that these carbons have the largest electron density and can easily interact with the positively charged region of the receptor. 
Table 4: Mulliken atomic charges distribution on TTF in the gas phase and different types of solvents

\begin{tabular}{|c|c|c|c|c|c|c|}
\hline \multirow{2}{*}{$\begin{array}{l}\text { TTF } \\
\mathrm{C}_{6} \mathrm{H}_{4} \mathrm{~S}_{4}\end{array}$} & \multicolumn{6}{|c|}{ Atomic charges } \\
\hline & Gas phase & Water & Acetone & THF & $\mathrm{CCL}_{4}$ & Benzene \\
\hline $1 \mathrm{C}$ & -0.470 & -0.462 & -0.461 & -0.441 & -0.463 & -0.463 \\
\hline $2 \mathrm{C}$ & -0.470 & -0.462 & -0.461 & -0.441 & -0.463 & -0.463 \\
\hline $3 \mathrm{C}$ & -0.138 & -0.150 & -0.149 & -0.238 & -0.143 & -0.143 \\
\hline $4 \mathrm{C}$ & -0.138 & -0.150 & -0.149 & -0.238 & -0.143 & -0.143 \\
\hline $5 \mathrm{C}$ & 0.138 & -0.150 & -0.149 & -0.238 & -0.143 & -0.143 \\
\hline $6 \mathrm{C}$ & 0.138 & -0.150 & -0.149 & -0.238 & -0.143 & -0.143 \\
\hline $7 \mathrm{~S}$ & 0.084 & 0.062 & 0.062 & 0.155 & 0.0714 & 0.0713 \\
\hline $8 \mathrm{~S}$ & 0.084 & 0.062 & 0.062 & 0.155 & 0.0714 & 0.0713 \\
\hline $9 S$ & 0.084 & 0.062 & 0.062 & 0.155 & 0.0714 & 0.0713 \\
\hline $10 \mathrm{~S}$ & 0.084 & 0.062 & 0.062 & 0.155 & 0.0714 & 0.0713 \\
\hline $11 \mathrm{H}$ & 0.289 & 0.319 & 0.318 & 0.304 & 0.303 & 0.303 \\
\hline $12 \mathrm{H}$ & 0.289 & 0.319 & 0.318 & 0.304 & 0.303 & 0.303 \\
\hline $13 \mathrm{H}$ & 0.289 & 0.319 & 0.318 & 0.304 & 0.303 & 0.303 \\
\hline $14 \mathrm{H}$ & 0.289 & 0.319 & 0.318 & 0.304 & 0.303 & 0.303 \\
\hline
\end{tabular}

The FFs of the system depicts the more reactive locations of this chemical, and these equations (9-14) use the Mulliken population to assess Fukui functions[30].

$f_{k}^{+}=q(N+1)-q(N)$.

$f_{k}^{-}=q(N)-q(N-1)$

$f_{k}^{0}=\frac{q(N+1)-q(N-1)}{2}$.

Where, $f_{k}^{+}$is a nucleophilic attack, $f_{k}^{-}$the electrophilic attack, and $f_{k}^{0}$ is a radical attack.

The nucleophilicity and electrophilicity were proposed by Morrel et al[30] and can be explained by the dual descriptor $\left(\Delta f_{(r)}\right)$.

$\Delta f_{(r)}=f_{k}^{+}-f_{k}^{-}$

If $\Delta f_{(r)}<0$, then the site is electrophile attack and if $\Delta f_{(r)}>0$ then the site is a nucleophile attack. On the other hand, local softness $\left(S_{k}^{+}, S_{k}^{-}, S_{k}^{0}\right)$ and local electrophilicity indices $\left(\omega_{k}^{+}, \omega_{k}^{-}, \omega_{k}^{0}\right)$ can be calculated by the following equations:

$S_{k}^{+}=S f_{k}^{+}, S_{k}^{-}=S f_{k}^{-}, S_{k}^{0}=S f_{k}^{0}$

$\omega_{k}^{+}=\omega f_{k}^{+}, \omega_{k}^{-}=\omega f_{k}^{-}, \omega_{k}^{0}=\omega f_{k}^{0}$.

Where + , - and 0 are design nucleophilic, electrophilic, and radical attack, respectively.

If $\Delta f_{(r)}<0$, then the site is electrophile attack and on the contrary if $\Delta f_{(r)}>0$, then the site is a nucleophile attack. The atomic charges on $(1 \mathrm{C}, 2 \mathrm{C}, 11 \mathrm{H}, 12 \mathrm{H}, 13 \mathrm{H}, 14 \mathrm{H})$ are electrophile attack while the atomic charges on $(3 \mathrm{C}, 4 \mathrm{C}, 5 \mathrm{C}, 6$ C, $7 \mathrm{~S}, 8 \mathrm{~S}, 9 \mathrm{~S}, 10 \mathrm{~S}$,) are nucleophile attack. The maximum value on $7 \mathrm{~S}, 8 \mathrm{~S}, 9 \mathrm{~S}, 10 \mathrm{~S}$ specifies that higher radical attack compared to other atoms as shown in Table 5.

Table 5: Fukui Functions for TTF from the NBO charges

\begin{tabular}{|l|c|c|c|c|c|c|c|}
\hline Atoms & $\mathbf{q}(\mathbf{N})$ & $\mathbf{q}(\mathbf{N}-1)$ & $\mathbf{q}(\mathbf{N}+\mathbf{1})$ & $f_{k}^{+}$ & $f_{k}^{-}$ & $f_{k}^{0}$ & $\boldsymbol{f}_{\boldsymbol{r}}$ \\
\hline $1 \mathrm{C}$ & -0.396 & -0.412 & -0.404 & -0.008 & 0.016 & 0.004 & -0.024 \\
\hline 2 C & -0.396 & -0.412 & -0.404 & -0.008 & 0.016 & 0.004 & -0.024 \\
\hline $3 \mathrm{C}$ & -0.400 & -0.416 & -0.374 & 0.026 & 0.016 & 0.021 & 0.01 \\
\hline 4 C & -0.400 & -0.416 & -0.374 & 0.026 & 0.016 & 0.021 & 0.01 \\
\hline $5 \mathrm{C}$ & -0.400 & -0.416 & -0.374 & 0.026 & 0.016 & 0.021 & 0.01 \\
\hline $6 \mathrm{C}$ & -0.400 & -0.416 & -0.374 & 0.026 & 0.016 & 0.021 & 0.01 \\
\hline $7 \mathrm{~S}$ & 0.325 & 0.148 & 0.518 & 0.193 & 0.177 & 0.185 & 0.016 \\
\hline $8 \mathrm{~S}$ & 0.325 & 0.148 & 0.518 & 0.193 & 0.177 & 0.185 & 0.016 \\
\hline $9 \mathrm{~S}$ & 0.325 & 0.148 & 0.518 & 0.193 & 0.177 & 0.185 & 0.016 \\
\hline $10 \mathrm{~S}$ & 0.325 & 0.148 & 0.518 & 0.193 & 0.177 & 0.185 & 0.016 \\
\hline $11 \mathrm{H}$ & 0.273 & 0.224 & 0.307 & 0.034 & 0.049 & 0.0415 & -0.015 \\
\hline $12 \mathrm{H}$ & 0.273 & 0.224 & 0.307 & 0.034 & 0.049 & 0.0415 & -0.015 \\
\hline $13 \mathrm{H}$ & 0.273 & 0.224 & 0.307 & 0.034 & 0.049 & 0.0415 & -0.015 \\
\hline $14 \mathrm{H}$ & 0.273 & 0.224 & 0.307 & 0.034 & 0.049 & 0.0415 & -0.015 \\
\hline
\end{tabular}

where,+- and 0 illustrate nucleophilic, electrophilic, and radical attack, respectively. Table 6 shows the local softness and local electrophilicity indices for selecting atomic locations for the TTF molecule. The greatest values of the entire three local 
electrophilicity reactivity descriptors $\left(S_{k}^{+}, f_{k}^{+}, \omega_{k}^{+}\right)$at $7 \mathrm{~S}, 8 \mathrm{~S}, 9$ $\mathrm{S}, 10 \mathrm{~S}$ atoms specify that this region is the nucleophile. Also, the maximum value of $\left(S_{k}^{-}, f_{k}^{-}, \omega_{k}^{-}\right)$at $7 \mathrm{~S}, 8 \mathrm{~S}, 9 \mathrm{~S}, 10 \mathrm{~S}$ atoms shows that this area is electrophile attack as shown in Table 6. The results show that the $\mathrm{S}$ atoms have an electrophile attack and nucleophile attack.

Table 6: Local softness and electrophilicity indices of the TTF molecule

\begin{tabular}{|l|c|c|c|c|c|c|}
\hline Atoms & $\boldsymbol{S}_{\boldsymbol{k}}^{+}$ & $\boldsymbol{S}_{\boldsymbol{k}}^{-}$ & $\boldsymbol{S}_{\boldsymbol{k}}^{\mathbf{0}}$ & $\boldsymbol{\omega}_{\boldsymbol{k}}^{+}$ & $\boldsymbol{\omega}_{\boldsymbol{k}}^{-}$ & $\boldsymbol{\omega}_{\boldsymbol{k}}^{\mathbf{0}}$ \\
\hline $\mathbf{1 ~ C}$ & -0.002 & 0.004 & 0.001 & -0.021 & 0.042 & 0.010 \\
\hline $\mathbf{2 ~ C}$ & -0.002 & 0.004 & 0.001 & -0.021 & 0.042 & 0.010 \\
\hline $\mathbf{3 ~ C}$ & 0.007 & 0.004 & 0.005 & 0.068 & 0.042 & 0.055 \\
\hline $\mathbf{4 ~ C}$ & 0.007 & 0.004 & 0.005 & 0.068 & 0.042 & 0.055 \\
\hline $\mathbf{5 ~ C}$ & 0.007 & 0.004 & 0.005 & 0.068 & 0.042 & 0.055 \\
\hline $\mathbf{6 ~ C}$ & 0.007 & 0.004 & 0.005 & 0.068 & 0.042 & 0.055 \\
\hline $\mathbf{7 ~ S}$ & 0.050 & 0.046 & 0.048 & 0.502 & 0.460 & 0.481 \\
\hline $\mathbf{8 ~ S}$ & 0.050 & 0.046 & 0.048 & 0.502 & 0.460 & 0.481 \\
\hline $\mathbf{9 ~ S}$ & 0.050 & 0.046 & 0.048 & 0.502 & 0.460 & 0.481 \\
\hline $\mathbf{1 0 ~ S}$ & 0.050 & 0.046 & 0.048 & 0.502 & 0.460 & 0.481 \\
\hline $\mathbf{1 1} \mathbf{~ H}$ & 0.009 & 0.013 & 0.011 & 0.088 & 0.127 & 0.108 \\
\hline $\mathbf{1 2} \mathbf{~ H}$ & 0.009 & 0.013 & 0.011 & 0.088 & 0.127 & 0.108 \\
\hline $\mathbf{1 3 ~ H}$ & 0.009 & 0.013 & 0.011 & 0.088 & 0.127 & 0.108 \\
\hline $\mathbf{1 4} \mathbf{~ H}$ & 0.009 & 0.013 & 0.011 & 0.088 & 0.127 & 0.108 \\
\hline
\end{tabular}

\section{3. Thermodynamic Properties}

The thermodynamic properties parameters such as thermal energy (E), entropy (S), and molar heat capacity $\left(C_{v}\right)$ of this compound in the gas phase, solvent phase, and in different temperatures were determined by DFT with the $6-311++\mathrm{G}$ as shown in Table $7 \& 8$ and Figure $2 \& 3$. TTF's thermal energy includes the total kinetic energy of all atoms in this molecule. The

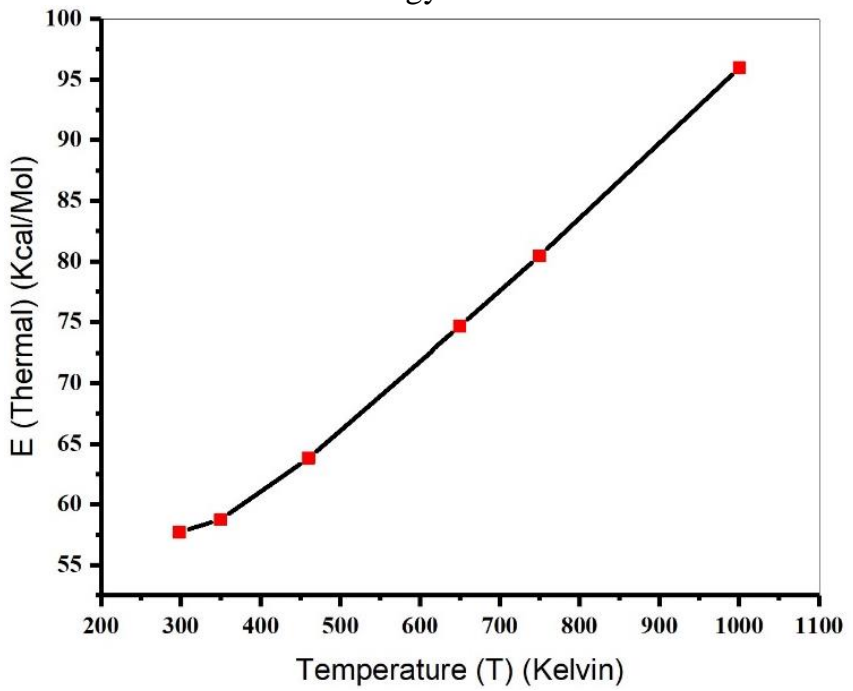

Figure 2: The relation between thermal energy and temperature study of thermodynamic characteristics is necessary in order to predict the outcome of a chemical reaction[36]. As displayed in Table 7, the thermal energy, entropy, and molar heat capacity values are changed from the gas phase to the solvent medium due to the solvent's polarity. These parameters are directly proportional to the values of temperature. Also, as temperatures rise, the molecular vibration increases.

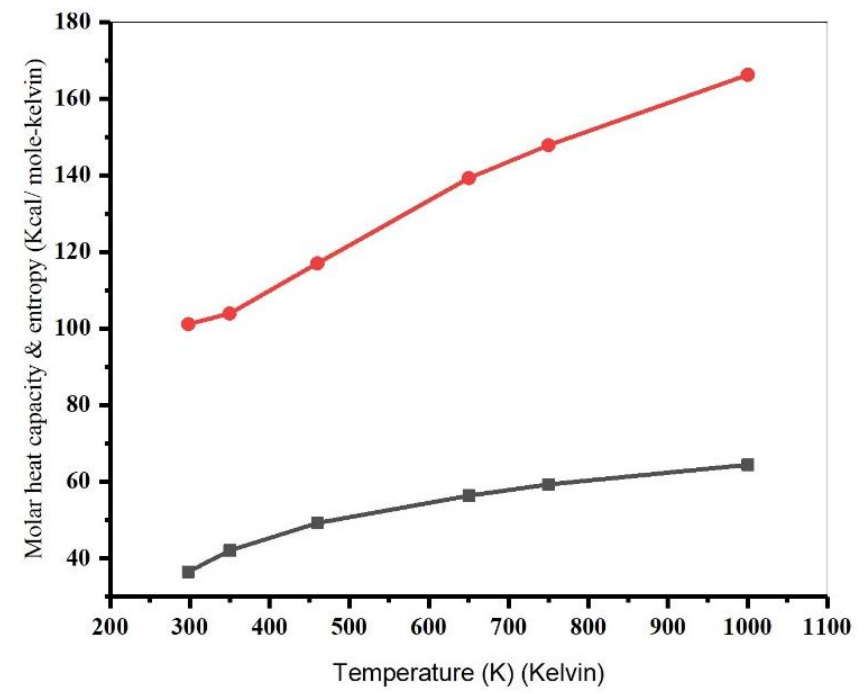

Figure 3: The relation between heat capacity and entropy with variation temperature

Table 7: The effective of solvents in thermodynamic parameters

\begin{tabular}{|l|c|c|c|c|c|c|}
\hline & Gas phase & Water & Acetone & THF & Benzene & $\mathrm{CCl}_{4}$ \\
\hline $\begin{array}{l}\mathrm{E}(\text { Thermal) } \\
\text { Kcal/Mol }\end{array}$ & 57.712 & 57.746 & 57.722 & 57.720 & 57.708 & 57.682 \\
\hline $\begin{array}{l}\text { Molar heat capacity (CV) } \\
\text { Cal/Mol-Kelvin }\end{array}$ & 36.540 & 36.549 & 36.583 & 36.576 & 36.566 & 36.604 \\
\hline $\begin{array}{l}\text { Entropy (S) } \\
\text { Cal/Mol-Kelvin }\end{array}$ & 101.146 & 101.112 & 100.617 & 100.634 & 100.821 & 100.429 \\
\hline
\end{tabular}




\section{Conclusion}

In this study, the solvent effect on frontier molecular orbitals, global chemical reactivity descriptors, dipole moment, Mulliken population analysis, and thermodynamic properties was analyzed and interpreted using Gaussian 09 software with the (B3LYP/6$311++\mathrm{G})$ basis sets.

The energy gap calculations demonstrated that electron transport from HOMO to LUMO is significantly easier in the gas phase than in the solvent phase.

The hardness, electronegativity, electrophilicity index, nucleofugality, and electrofugality declined as the solvent transitioned from polar to non-polar. Softness and chemical potential, on the other hand, reduced as the solvent changed from non-polar to polar.

It also demonstrates that the solvent has no effect on the dipole moments because TTF is a non-polar molecule.

Mulliken population analysis for nucleophilic and electrophilic charges distribution successfully estimate the reactive region.

Fukui Function (FFs) benefits to identify the nucleophilic and electrophilic nature of a specific region within a molecule.

Thermodynamic properties such as thermal energy and molar heat capacity increase as the temperature and polarity of the solvents rise, whereas entropy decreases as the polarity of the molecule rises. These thermodynamical properties give a useful information for the future study on the titles compound.

We conclude that the TTF compound is an excellent object for future studies of semiconductor and optoelectronic material.

\section{Acknowledgements}

This work was supported by the university of Halabja and Garmian university.

\section{References}

1. Broggi, J., Terme, T., and Vanelle, P., 2014. Organic Electron Donors as Powerful Single-Electron Reducing Agents in Organic Synthesis, Angewandte Chemie International Edition, 53(2), 384-413.

2. Łapiński, A., 2016. Vibrational and Electronic Structure, Electron-Electron and Electron-Phonon Interactions in Organic Conductors Investigated by Optical Spectroscopy, Applications of Molecular Spectroscopy to Current Research in the Chemical and Biological Sciences, 113.

3. Pop, F., Riobé, F.o., Seifert, S., Cauchy, T., Ding, J., Dupont, N., Hauser, A., Koch, M., and Avarvari, N., 2013. Tetrathiafulvalene-1, 3, 5-triazines as (Multi) DonorAcceptor Systems with Tunable Charge Transfer: Structural, Photophysical, and Theoretical Investigations, Inorganic chemistry, 52(9), 5023-5034.

4. Bendjeddou, A., Abbaz, T., Gouasmia, A., and Villemin, D., 2016. Studies on Chemical Reactivity of p-aminophenyl Benzene-Fused Bis Tetrathiafulvalenes Through Quantum Chemical Approaches, American Journal of Applied Chemistry, 4(3), 104-110.

5. Jeroundi, D., Chakroune, S., Elmsellem, H., El Hadrami, E., Ben-Tama, A., Elyoussfi, A., Dafali, A., Douez, C., and Hafez, B., 2017. 2, 3-(2-alkylthio)-6, 7-bis (2-alkylthio) TTF: a new and green synthetic anti-corrosive inhibitors for mild steel in $1.0 \mathrm{HCl}$.

6. Schröder, H.V. and Schalley, C.A., 2018. Tetrathiafulvalene-a redox-switchable building block to control motion in mechanically interlocked molecules, Beilstein journal of organic chemistry, 14(1), 2163-2185.

7. Jiang, H., Mazzanti, V., Parker, C.R., Broman, S.L., Wallberg, J.H., Lušpai, K., Brincko, A., Kjaergaard, H.G., Kadziola, A., and Rapta, P., 2015. Interactions between tetrathiafulvalene units in dimeric structures-the influence of cyclic cores, Beilstein journal of organic chemistry, 11(1), 930-948.
8. Gnanamozhi, P., Pandiyan, V., Srinivasan, P., and Stephen, A.D., 2019. Exploring the Structure, Electron Density and HOMO-LUMO Studies of Tetrathiafulvalene (TTF) as Organic Superconductors: A DFT and AIM Analysis, Journal of Atomic, Molecular, Condensate and Nano Physics, 6(1), 33-43.

9. U.D. Thangaraj, M. Rajagantham, K. Govindarajulu, J.P. Arulsamy, Journal of Physical Science 28 (2017).

10. Flores-Holguín, N., Frau, J., and Glossman-Mitnik, D., 2019. A Comparison of Conceptual DFT and Molecular Electron Density Theory (MEDT) Descriptors of Local Chemical Reactivity Properties: Oxytocin and Vasopressin Peptide Hormones as Test Cases, MOJ Bioorganic Org. Chem, 2, 45-49.

11. HEKIM, S., Azeez, Y.H., and Akpinar, S., The Theoretical Investigation of the HOMO, LUMO energies and Chemical Reactivity of C9H12 and C7F3NH5Cl Molecules, Journal of Physical Chemistry and Functional Materials, 2(1), 28-30.

12. Qader, I.N., Mohammad, A., Azeez, Y.H., Agid, R.S., Hassan, H.S., and Al-Nabawi, S.H.M., Chemical Structural and Vibrational Analysis of Potassium Acetate: A Density Function Theory Study, Journal of Physical Chemistry and Functional Materials, 2(1), 22-24.

13. Bharanidharan, S., Saleem, H., Subashchandrabose, S., Suresh, M., and Babu, N.R., 2017. FT-IR, FT-Raman and UV-Visible Spectral Analysis on (E)-N'-(thiophen-2ylmethylene) Nicotinohydrazide, Arch Chem Res, 1, 2.

14. Demircioğlu, Z., Kaştaş, Ç.A., and Büyükgüngör, O., 2015. Theoretical analysis (NBO, NPA, Mulliken Population Method) and molecular orbital studies (hardness, chemical potential, electrophilicity and Fukui function analysis) of (E)-2-((4-hydroxy2-methylphenylimino) methyl)-3-methoxyphenol, Journal of Molecular Structure, 1091, 183-195.

15. Ismail, R., Suleiman, A., Gidado, A., Lawan, A., and Musa, A., 2019. Investigation of the Effects of Solvents on the Structural, Electronic and Thermodynamic Properties of Rosiglitazone Based on Density Functional Theory, Physical Science International Journal, 1-18.

16. Wang, Y., Liu, Q., Qiu, L., Wang, T., Yuan, H., Lin, J., and Luo, S., 2015. Molecular structure, IR spectra, and chemical reactivity of cisplatin and transplatin: DFT studies, basis set effect and solvent effect, Spectrochimica Acta Part A: Molecular and Biomolecular Spectroscopy, 150, 902-908.

17. Moorthy, N., Jobe Prabakar, P., Ramalingam, S., Periandy, S., and Pandian, G., 2015. Spectroscopic investigation of the stimulus of NLO property on acetone thiosemicarbazone using computational [HF and DFT] confinement, J Theor Comput Sci, 2(137), 2.

18. Babu, N.S. and Jayaprakash, D., 2015. Global and reactivity descriptors studies of cyanuric acid tautomers in different solvents by using of density functional theory (DFT), HOMO, $1,1$.

19. Canevet, D., Salle, M., Zhang, G., Zhang, D., and Zhu, D., 2009. Tetrathiafulvalene (TTF) derivatives: key building-blocks for switchable processes, Chemical Communications, (17), 2245-2269.

20. Vektariene, A., Vektaris, G., and Svoboda, J., 2009. A theoretical approach to the nucleophilic behavior of benzofused thieno [3, 2-b] furans using DFT and HF based reactivity descriptors, Arkivoc: Online Journal of Organic Chemistry.

21. Islam, M.J., Kumer, A., Sarker, N., Paul, S., and Zannat, A., 2019. The prediction and theoretical study for chemical reactivity, thermophysical and biological activity of morpholinium nitrate and nitrite ionic liquid crystals: A DFT study, Advanced Journal of Chemistry-Section A (Theoretical, Engineering and Applied Chemistry), 2(4, pp. 266-385), 316-326.

22. E. AlShamaileh, Computational Chemistry 2 (2014) 43.

23. Flores-Holguín, N., Frau, J., and Glossman-Mitnik, D., 2019. Chemical reactivity and bioactivity properties of the Phallotoxin family of fungal peptides based on Conceptual Peptidology and DFT study, Heliyon, 5(8), e02335.

24. Frisch MJ, Trucks GW, Schlegel HB, Scuseria GE, Robb MA, Cheeseman JR, Scalmani G, Barone V, Mennucci B, Petersson GA, Nakatsuji H, Caricato M, Li X, Hratchian HP, Izmaylov AF, Bloino J, Zheng G, Sonnenberg JL, Hada M, Ehara M, Toyota K, Fukuda R, Hasegawa J, Ishida M, Nakajima T, Honda Y, Kitao O, Nakai 
H, Vreven T, Montgomery Jr. J A, Peralta J E, Ogliaro F, Bearpark M, Heyd J J, Brothers E, Kudin KN, Staroverov VN, Keith T, Kobayashi R, Normand J, Raghavachari K, Rendell A, Burant JC, Iyengar SS, Tomasi J, Cossi M, Rega N, Millam JM, Klene M, Knox JE, Cross JB, Bakken V, Adamo C, Jaramillo J, Gomperts R, Stratmann RE, Yazyev O, Austin AJ, Cammi R, Pomelli C, Ochterski JW, Martin RL, Morokuma K, Zakrzewski VG, Voth GA, Salvador P, Dannenberg JJ, Dapprich S, Daniels AD, Farkas O, Foresman JB, Ortiz JV, Cioslowskiand J, Fox DJ (2009) Gaussian 09,Revision B.01,Gaussian Inc. J Comput Chem, 30: 2785

25. Abbaz, T., Bendjeddou, A., and Villemin, D., 2018. Molecular structure, HOMO, LUMO, MEP, natural bond orbital analysis of benzo and anthraquinodimethane derivatives, Pharmaceutical and Biological Evaluations, 5(2), 27-39.

26. Villemin, D., Abbaz, T., and Bendjeddou, A., 2018. Molecular structure, HOMO, LUMO, MEP, natural bond orbital analysis of benzo and anthraquinodimethane derivatives.

27. Parr, R.G. and Pearson, R.G., 1983. Absolute hardness: companion parameter to absolute electronegativity, Journal of the American Chemical Society, 105(26), 75127516.

28. Srivastava, K., Shimpi, M.R., Srivastava, A., Tandon, P., Sinha, K., and Velaga, S.P., 2016. Vibrational analysis and chemical activity of paracetamol-oxalic acid cocrystal based on monomer and dimer calculations: DFT and AIM approach, RSC Advances, 6(12), 10024-10037.

29. Khan, M.F., Rashid, R., Rahman, M.M., Al Faruk, M., RAHMAN, M.M., and RASHID, M.A., 2017. Effects of solvent polarity on solvation free energy, dipole moment, polarizability, hyperpolarizability and molecular reactivity of aspirin, Int. J. Pharm. Pharm. Sci, 9(2), 217-221.

30. Parr, R.G. and Yang, W., 1984. Density functional approach to the frontier-electron theory of chemical reactivity, Journal of the American Chemical Society, 106(14), 4049-4050.

31. Beltrán, J.I, Flores, F., Martínez, J.I., and Ortega, J.J.T.J.o.P.C.C., 2013. Energy Level Alignment in Organic-Organic Heterojunctions: The TTF/TCNQ Interface, 117(8), 3888-3894.

32. Gnanamozhi, P., Pandiyan, V., Srinivasan, P., and Stephen, A.D., 2019. Exploring the Structure, Electron Density and HOMO-LUMO Studies of Tetrathiafulvalene (TTF) as Organic Superconductors: A DFT and AIM.

33. Ebenso, E.E., Khaled, K., Shukla, S.K., Singh, A.K., Eddy, N., Saracoglu, M., Murulana, L.C., Kandemirli, F., Arslan, T., and Obot, I., 2012. Quantum chemical investigations on quinoline derivatives as effective corrosion inhibitors for mild steel in acidic medium.

34. Sarker, M.N., Kumer, A., Islam, M.J., and Paul, S., 2019. A computational study of thermophysical, HOMO, LUMO, vibrational spectrum and UV-visible spectrum of cannabicyclol (CBL), and cannabigerol (CBG) using DFT, Asian Journal of Nanosciences and Materials, 2(4), 439-447.

35. Vidhya, V., Austine, A., and Arivazhagan, M., 2019. Quantum chemical determination of molecular geometries and spectral investigation of 4-ethoxy-2, 3difluoro benzamide, Heliyon, 5(11), e02365.

36. Sangeetha, R., Seshadri, S., and MP, R., Sperctroscopic, Electronic Structure And Homo Lumo Analsis Of 4-Bromo-2-Fluoro-1-Nitrobenzene. 